\title{
Explicit Analytic Solution of Vibration Equation for large domain by mean of the Elzaki projected Differential Transform Method
}

\author{
Muhammad Suleman ${ }^{\mathrm{a}, \mathrm{b}}$, Qingbiao $\mathrm{Wu}^{\mathrm{a}}$, T. M. Elzaki ${ }^{\mathrm{c}, \mathrm{d}}$, \\ ${ }^{a}$ Department of Mathematics Zhejiang University, Hangzhou, Zhejiang, China \\ ${ }^{b}$ Department of Mathematics, Comsat institute of Information Technology, Islamabad, Pakistan \\ 'Mathematics Department, Faculty of Sciences and Arts, University of Jeddah, Jeddah-Saudi Arabia

\section{Abstract} \\ ${ }^{\mathrm{d}}$ Mathematics Department, Sudan University of Science and Technology
}

The aim of this paper is to present a reliable and efficient algorithm Elzaki projected differential transform method (EPDTM) to obtain the explicit solution of vibration equation for a very large membrane with given initial conditions. By using initial conditions, explicit series solutions for six different cases have been derived for the fast convergence of the solution. Numerical results show the reliability, efficiency and accuracy of Elzaki projected differential transform method (EPDTM). Numerical results for the six different cases are presented graphically.

\section{Keywords}

Elzaki projected differential transform method; explicit series solution; vibration equation; large membrane; initial condition

\section{Academic Discipline And Sub-Disciplines}

Applied Mathematics

\section{Subject Classification}

35B40, 35Q55, 76D05

\section{Council for Innovative Research}

Peer Review Research Publishing System

\section{Journal: JOURNAL OF ADVANCES IN MATHEMATICS}

Vol .11, No. 5

www.cirjam.com , editorjam@gmail.com 


\section{Introduction}

In many problems arises in area of science and engineering for large membranes, vibration analysis plays an important role to determine the properties and behavior of vibrations. Vibration arises in music, acoustics membranes, microphones, speaker and numerous other devices. Human tissues and eardrum also shows vibrational characteristics and hearing aid devices are designed after understanding the vibrational behavior of membranes. Linear combination of the modes of structure can be used to explained vibrations. Alternatively propagation of wave travelling in a membrane structure, vibration can also cause the destruction of membrane structure in engineering, so characteristics of vibration of membrane and its dynamic response under the effect of external force become a great important scientific issue and number of researchers studied propagation, transmission and reflection of vibrations, like Tapaswini and Chakraverty studied non probabilistic solution of vibration equation using ADM [10], Yidrim studied the solution of vibration equation of a large membrane using HPM [7], Mohyud-din and Yildrim studied and analyzed the fractional vibrational equation for large membrane [9], further can studied in literature. In this paper we apply Elzaki projected differential transform method (EPDTM) $[1,2,3]$ to solve the vibration equation and different cases has been discussed, numerical and graphical results are found with the help of Maple. In section 2, basic idea of Elzaki transform and projected differential transform method is explained. Solution of the problem can be studied in section 3 and some results and conclusion are discussed in section 4.

\section{Basic idea of the method}

\subsection{Elzaki Transformation}

Elzaki transform was introduced by Tarig. M. Elzaki in [3]. From the classical Fourier integral, Like Sumudu transform, Laplace transform and Fourier transform, Elzaki transform is used to simplify the process of solving ordinary and partial differential equations in the time domain. Mathematical formulation of Elzaki transformation is as follows:

$$
A=\left\{f(t): \exists M, k_{1}, k_{2}>0,|f(t)|<M e^{\frac{k}{k}}, \text { if } \quad t \in(-1)^{j} *[0, \infty)\right\}
$$

For a given function in set $A$, the constant $M$ must be finite number $k_{1}, k_{2}$ maybe finite or infinite. Elzaki transform is denoted by $E($.$) and defined by the integral equation,$

$$
\mathrm{E}[\mathrm{f}(\mathrm{t})]=\mathrm{T}(\mathrm{v})=\mathrm{v} \int_{0}^{\infty} \mathrm{f}(\mathrm{t}) \mathrm{e}^{\frac{-\mathrm{t}}{\mathrm{v}}} \mathrm{dt}, \quad \mathrm{t}>0, \mathrm{k}_{1} \leq \mathrm{v} \leq \mathrm{k}_{2},
$$

Where variable ' $v$ ' is used in the transformation to the factor the variable ' $t$ ' in the argument of the function.

\subsection{Projected Differential Transform Method}

The basic idea of Projected Differential Transform Method (PDTM) was given by Tarig. Elzaki in [1, 2], by letting $f\left(u_{1}, u_{2, \ldots}\right.$ $u_{n}$ ) is defined as

$$
\mathrm{f}\left(\mathrm{u}_{1}, \mathrm{u}_{2}, \ldots \mathrm{u}_{\mathrm{n}}\right)=\frac{1}{\mathrm{k} !}\left[\frac{\partial^{\mathrm{k}} \mathrm{f}\left(\mathrm{u}_{1}, \mathrm{u}_{2}, \ldots \mathrm{u}_{\mathrm{n}}\right)}{\partial \mathrm{u}_{\mathrm{n}}^{\mathrm{k}}}\right]_{\mathrm{u}_{\mathrm{n}}=0}
$$

such that $\mathrm{f}\left(\mathrm{u}_{1}, \mathrm{u}_{2}, \ldots \mathrm{u}_{\mathrm{n}}\right)$ is the given function and $\mathrm{f}\left(\mathrm{u}_{1}, \mathrm{u}_{2}, \ldots \mathrm{u}_{\mathrm{n}-1}, \mathrm{k}\right)$ is the projected transformed function, and the Inverse differential transform of $\mathrm{f}\left(\mathrm{u}_{1}, \mathrm{u}_{2}, \ldots \mathrm{u}_{\mathrm{n}-1}, \mathrm{k}\right)$ is defined as

$$
\mathrm{f}\left(\mathrm{u}_{1}, \mathrm{u}_{2}, \ldots \mathrm{u}_{\mathrm{n}}\right)=\sum_{\mathrm{k}=0}^{\infty} \mathrm{f}\left(\mathrm{u}_{1}, \mathrm{u}_{2}, \ldots \mathrm{u}_{\mathrm{n}-1}, \mathrm{k}\right)\left(\mathrm{u}-\mathrm{u}_{0}\right)^{\mathrm{k}}
$$

Some fundamental theorems [1] is given below

(1) If $\mathrm{f}\left(\mathrm{u}_{1}, \mathrm{u}_{2}, \ldots \mathrm{u}_{\mathrm{n}}\right)=\phi\left(\mathrm{u}_{1}, \mathrm{u}_{2}, \ldots \mathrm{u}_{\mathrm{n}}\right) \pm \psi\left(\mathrm{u}_{1}, \mathrm{u}_{2}, \ldots \mathrm{u}_{\mathrm{n}}\right)$

$$
\text { then } \mathrm{z}\left(\mathrm{u}_{1}, \mathrm{u}_{2}, \ldots \mathrm{u}_{\mathrm{n}-1}, \mathrm{k}\right)=\phi\left(\mathrm{u}_{1}, \mathrm{u}_{2}, \ldots \mathrm{u}_{\mathrm{n}-1}, \mathrm{k}\right) \pm \psi\left(\mathrm{u}_{1}, \mathrm{u}_{2}, \ldots \mathrm{u}_{\mathrm{n}-1}, \mathrm{k}\right)
$$

(2) If $\mathrm{f}\left(\mathrm{u}_{1}, \mathrm{u}_{2}, \ldots \mathrm{u}_{\mathrm{n}}\right)=\mathrm{c} \phi\left(\mathrm{u}_{1}, \mathrm{u}_{2}, \ldots \mathrm{u}_{\mathrm{n}}\right)$

then $\mathrm{f}\left(\mathrm{u}_{1}, \mathrm{u}_{2}, \ldots \mathrm{u}_{\mathrm{n}-1}, \mathrm{k}\right)=\mathrm{c} \phi\left(\mathrm{u}_{1}, \mathrm{u}_{2}, \ldots \mathrm{u}_{\mathrm{n}-1}, \mathrm{k}\right)$

(3) If $\mathrm{f}\left(\mathrm{u}_{1}, \mathrm{u}_{2}, \ldots \mathrm{u}_{\mathrm{n}}\right)=\frac{\mathrm{d} \phi\left(\mathrm{u}_{1}, \mathrm{u}_{2}, \ldots \mathrm{u}_{\mathrm{n}}\right)}{\mathrm{du} \mathrm{u}_{\mathrm{n}}}$

then $\mathrm{f}\left(\mathrm{u}_{1}, \mathrm{u}_{2}, \ldots \mathrm{u}_{\mathrm{n}-1}, \mathrm{k}\right)=(\mathrm{k}+1) \phi\left(\mathrm{u}_{1}, \mathrm{u}_{2}, \ldots \mathrm{u}_{\mathrm{n}-1}, \mathrm{k}+1\right)$ 
(4) If $\mathrm{f}\left(\mathrm{u}_{1}, \mathrm{u}_{2}, \ldots \mathrm{u}_{\mathrm{n}}\right)=\frac{\mathrm{d}^{\mathrm{n}} \phi\left(\mathrm{u}_{1}, \mathrm{u}_{2}, \ldots \mathrm{u}_{\mathrm{n}}\right)}{\mathrm{du_{n } ^ { n }}}$ then $\mathrm{f}\left(\mathrm{u}_{1}, \mathrm{u}_{2}, \ldots \mathrm{u}_{\mathrm{n}-1}, \mathrm{k}\right)=\frac{\mathrm{k}+\mathrm{n}) !}{\mathrm{k} !} \phi\left(\mathrm{u}_{1}, \mathrm{u}_{2}, \ldots \mathrm{u}_{\mathrm{n}-1}, \mathrm{k}+\mathrm{n}\right)$

(5) If $\mathrm{f}\left(\mathrm{u}_{1}, \mathrm{u}_{2}, \ldots \mathrm{u}_{\mathrm{n}}\right)=\phi\left(\mathrm{u}_{1}, \mathrm{u}_{2}, \ldots \mathrm{u}_{\mathrm{n}}\right) \psi\left(\mathrm{u}_{1}, \mathrm{u}_{2}, \ldots \mathrm{u}_{\mathrm{n}}\right)$

$$
\text { then } \mathrm{f}\left(\mathrm{u}_{1}, \mathrm{u}_{2}, \ldots \mathrm{u}_{\mathrm{n}-1}, \mathrm{k}\right)=\sum_{\mathrm{m}=0}^{\mathrm{k}} \phi\left(\mathrm{u}_{1}, \mathrm{u}_{2}, \ldots \mathrm{u}_{\mathrm{n}-1}, \mathrm{~m}\right) \psi\left(\mathrm{u}_{1}, \mathrm{u}_{2}, \ldots \mathrm{u}_{\mathrm{n}-1}, \mathrm{k}-\mathrm{m}\right)
$$

(6) If $\mathrm{f}\left(\mathrm{u}_{1}, \mathrm{u}_{2}, \ldots \mathrm{u}_{\mathrm{n}}\right)=\phi_{1}\left(\mathrm{u}_{1}, \mathrm{u}_{2}, \ldots \mathrm{u}_{\mathrm{n}}\right) \phi_{2}\left(\mathrm{u}_{1}, \mathrm{u}_{2}, \ldots \mathrm{u}_{\mathrm{n}}\right) \ldots . \phi_{\mathrm{n}}\left(\mathrm{u}_{1}, \mathrm{u}_{2}, \ldots \mathrm{u}_{\mathrm{n}}\right)$

then

$$
\begin{gathered}
\mathrm{f}\left(\mathrm{u}_{1}, \mathrm{u}_{2}, \ldots \mathrm{u}_{\mathrm{n}-1}, \mathrm{k}\right)=\sum_{\mathrm{k}_{\mathrm{n}-1}=0 \mathrm{k}_{\mathrm{n}-2}=0}^{\mathrm{k}} \sum_{\mathrm{k}_{2}=0}^{\mathrm{k}_{\mathrm{n}-1}} \ldots . \sum_{\mathrm{k}_{1}=0}^{\mathrm{k}_{3}} \sum_{1}^{\mathrm{k}_{2}} \phi_{1}\left(\mathrm{u}_{1}, \mathrm{u}_{2}, \ldots \mathrm{u}_{\mathrm{n}-1}, \mathrm{k}_{1}\right) \phi_{2}\left(\mathrm{u}_{1}, \mathrm{u}_{2}, \ldots \mathrm{u}_{\mathrm{n}-1}, \mathrm{k}_{2}-\mathrm{k}_{1}\right) \\
\ldots . \phi_{\mathrm{n}-1}\left(\mathrm{u}_{1}, \mathrm{u}_{2}, \ldots \mathrm{u}_{\mathrm{n}-1}, \mathrm{k}_{\mathrm{n}-1}-\mathrm{k}_{\mathrm{n}}\right) \phi_{\mathrm{n}}\left(\mathrm{u}_{1}, \mathrm{u}_{2}, \ldots \mathrm{u}_{\mathrm{n}-1}, \mathrm{k}-\mathrm{k}_{\mathrm{n}-1}\right)
\end{gathered}
$$

(7) If $\mathrm{f}\left(\mathrm{u}_{1}, \mathrm{u}_{2}, \ldots \mathrm{u}_{\mathrm{n}}\right)=\mathrm{u}_{1}^{\mathrm{q}_{1}} \mathrm{u}_{2}^{\mathrm{q}_{2}} \mathrm{u}_{3}^{\mathrm{q}_{3}} \ldots ., \mathrm{u}_{\mathrm{n}}^{\mathrm{q}_{\mathrm{n}}}$

$$
\text { then } f\left(u_{1}, u_{2}, \ldots u_{n-1}, k\right)=\delta\left(u_{1}, u_{2}, \ldots u_{n-1}, q_{n}-k\right)=\left\{\begin{array}{cc}
1 & q_{n}=k \\
0 & q_{n} \neq k
\end{array}\right.
$$

\section{Solution of Vibration equation using EPDTM}

Consider an open disk of radius ' $x$ ' centered at origin representing a shape of 'still' drum head. Due to circular geometry of disk we use cylindrical co-ordinates so the mode of vibration of radially symmetric circular drum having radius ' $x$ ', then the function $\phi$ does not depend on angular displacement " $\theta$ ", so the vibration equation simplifies to the equation

$\frac{1}{\mathrm{c}^{2}} \frac{\partial^{2} \phi}{\partial \mathrm{t}^{2}}=\frac{\partial^{2} \phi}{\partial \mathrm{x}^{2}}+\frac{1}{\mathrm{x}} \frac{\partial \phi}{\partial \mathrm{x}}, \quad \mathrm{x} \geq 0, \mathrm{t} \geq 0$

with initial conditions

$\phi(\mathrm{x}, 0)=\mathrm{f}(\mathrm{x})$

and

$\phi_{\mathrm{t}}(\mathrm{x}, 0)=\operatorname{cg}(\mathrm{x})$,

Where $\phi(x, t)$ represents the displacement of finding a particle at the point ' $x$ ' in the instant $t, c$ is the wave velocity of free vibration. To solve Eq. (5) by Elzaki projected differential transform method, first we apply the Elzaki transform on both sides

$\mathrm{E}\left[\phi_{\mathrm{tt}}\right]=\mathrm{E}\left[\mathrm{c}^{2} \phi_{\mathrm{xx}}+\frac{\mathrm{c}^{2}}{\mathrm{x}} \phi_{\mathrm{x}}\right]$,

$\frac{1}{\mathrm{v}^{2}} \mathrm{E}(\phi)-\phi(0)-\mathrm{v} \phi^{\prime}(0)=\mathrm{E}\left[\mathrm{c}^{2} \phi_{\mathrm{xx}}+\frac{\mathrm{c}^{2}}{\mathrm{x}} \phi_{\mathrm{x}}\right]$,

$\mathrm{E}(\phi)-\mathrm{v}^{2} \mathrm{f}(\mathrm{x})-\mathrm{v}^{3} \operatorname{cg}(\mathrm{x})=\mathrm{v}^{2} \mathrm{E}\left[\mathrm{c}^{2} \phi_{\mathrm{xx}}+\frac{\mathrm{c}^{2}}{\mathrm{x}} \phi_{\mathrm{x}}\right]$,

$\mathrm{E}(\phi)=\mathrm{v}^{2} \mathrm{f}(\mathrm{x})+\mathrm{v}^{3} \operatorname{cg}(\mathrm{x})+\mathrm{v}^{2} \mathrm{E}\left[\mathrm{c}^{2} \phi_{\mathrm{xx}}+\frac{\mathrm{c}^{2}}{\mathrm{x}} \phi_{\mathrm{x}}\right]$,

by applying the inverse Elzaki transform 
$\phi(x, t)=f(x)+\operatorname{tcg}(x)+E^{-1}\left[v^{2} E\left(c^{2} \phi_{x x}+\frac{c^{2}}{x} \phi_{x}\right)\right]$,

now by applying projected differential transform method we have the following equation.

$\phi(\mathrm{x}, \mathrm{m}+1)=\mathrm{E}^{-1}\left[\mathrm{v}^{2} \mathrm{E}\left(\mathrm{c}^{2} \mathrm{~A}_{\mathrm{m}+1}+\frac{\mathrm{c}^{2}}{\mathrm{x}} \mathrm{B}_{\mathrm{m}+1}\right)\right], \quad \phi(\mathrm{x}, 0)=\mathrm{f}(\mathrm{x})+\operatorname{ctg}(\mathrm{x})$,

where $\mathrm{A}_{\mathrm{m}+1}=\frac{\partial^{2} \phi(\mathrm{x}, \mathrm{m})}{\partial \mathrm{x}^{2}}$ and $\mathrm{B}_{\mathrm{m}+1}=\frac{\partial \phi(\mathrm{x}, \mathrm{m})}{\partial \mathrm{x}}$

$\phi(x, 1)=E^{-1}\left[v^{2} E\left(c^{2} A_{1}+\frac{c^{2}}{x} B_{1}\right)\right]$,

$\phi(x, 2)=E^{-1}\left[v^{2} E\left(c^{2} A_{2}+\frac{c^{2}}{x} B_{2}\right)\right]$

$\phi(x, 3)=E^{-1}\left[v^{2} E\left(c^{2} A_{3}+\frac{c^{2}}{x} B_{3}\right)\right]$,

and so on.

\subsection{Particular cases}

\section{Case I:}

when $f(x)=x$ and $g(x)=1$

so by Eq. (9),

$\phi(\mathrm{x}, 0)=\mathrm{x}+\mathrm{ct}$

by using the above equation we can find the values of $\phi(x, 1), A_{1}=0, B_{1}=1$

$$
\begin{aligned}
\phi(x, 1) & =E^{-1}\left[v^{2} E\left(c^{2}(0)+\frac{c^{2}}{x}(1)\right)\right] \\
& =E^{-1}\left[v^{2} E\left(\frac{c^{2}}{x}\right)\right] \\
& =E^{-1}\left[v^{2}\left(\frac{c^{2}}{x} v^{2}\right)\right] \\
& =E^{-1}\left[\left(\frac{c^{2}}{x} v^{4}\right)\right] \\
& =\frac{c^{2}}{x} \frac{t^{2}}{2 !} \\
& =\frac{c^{2} t^{2}}{2 x}
\end{aligned}
$$

Now $A_{2}=\frac{c^{2} t^{2}}{x^{3}}, \quad B_{2}=-\frac{c^{2} t^{2}}{2 x^{2}}$

so $\phi(x, 2)=\frac{c^{4} t^{4}}{24 x^{3}}$,

$$
\begin{aligned}
& A_{3}=\frac{c^{4} t^{4}}{2 x^{5}}, \quad B_{2}=-\frac{c^{4} t^{4}}{8 x^{4}}, \\
& \phi(x, 3)=\frac{c^{6} t^{6}}{80 x^{5}},
\end{aligned}
$$

and so on. Therefore, 


$$
\begin{aligned}
\phi(\mathrm{x}, \mathrm{t})= & \phi(\mathrm{x}, 0)+\phi(\mathrm{x}, 1)+\phi(\mathrm{x}, 2)+\phi(\mathrm{x}, 3)+\ldots ., \\
& =\mathrm{x}+\mathrm{ct}+\frac{\mathrm{c}^{2} \mathrm{t}^{2}}{2 \mathrm{x}}+\frac{\mathrm{c}^{4} \mathrm{t}^{4}}{24 \mathrm{x}^{3}}+\frac{\mathrm{c}^{6} \mathrm{t}^{6}}{80 \mathrm{x}^{5}}+\ldots ., \\
& =\mathrm{x}\left[1+\mathrm{c}\left(\frac{\mathrm{t}}{\mathrm{x}}\right)+\frac{\mathrm{c}^{2}}{2}\left(\frac{\mathrm{t}}{\mathrm{x}}\right)^{2}+\frac{\mathrm{c}^{4}}{24}\left(\frac{\mathrm{t}}{\mathrm{x}}\right)^{4}+\frac{\mathrm{c}^{6}}{80}\left(\frac{\mathrm{t}}{\mathrm{x}}\right)^{6}+\ldots .\right],
\end{aligned}
$$

The above series will be convergent for $|\mathrm{t} / \mathrm{x}|<<1 \mathrm{i}$. e. for a small range of time and large membrane

\section{Case II:}

when $f(x)=x^{2}$ and $g(x)=1$

$\phi(\mathrm{x}, 0)=\mathrm{x}^{2}+\mathrm{ct}$,

using the above equations we have,

$A_{1}=2$ and $B_{2}=2 x$

$$
\begin{aligned}
\phi(x, 1) & =E^{-1}\left[\mathrm{v}^{2} \mathrm{E}\left(\mathrm{c}^{2}(2)+\frac{\mathrm{c}^{2}}{\mathrm{x}}(2 \mathrm{x})\right)\right], \\
& =\mathrm{E}^{-1}\left[\mathrm{v}^{2} \mathrm{E}\left(2 \mathrm{c}^{2}+2 \mathrm{c}^{2}\right)\right] \\
& =\mathrm{E}^{-1}\left[\mathrm{v}^{2}\left(4 \mathrm{c}^{2} \mathrm{v}^{2}\right)\right] \\
& =\mathrm{E}^{-1}\left[\left(4 \mathrm{c}^{2} \mathrm{v}^{4}\right)\right] \\
& =4 \mathrm{c}^{2} \frac{\mathrm{t}^{2}}{2 !} \\
& =2 \mathrm{c}^{2} \mathrm{t}^{2}
\end{aligned}
$$

now $A_{2}=0$ and $B_{2}=0$

$\phi(\mathrm{x}, 2)=0$,

so we can write,

$\phi(\mathrm{x}, \mathrm{n})=0, \quad \mathrm{n} \geq 2$

Therefore solution is of the form

$\phi(\mathrm{x}, \mathrm{t})=\phi(\mathrm{x}, 0)+\phi(\mathrm{x}, 1)+\phi(\mathrm{x}, 2)+\phi(\mathrm{x}, 3)+\ldots .$,

$$
=\mathrm{x}^{2}+\mathrm{ct}+2 \mathrm{c}^{2} \mathrm{t}^{2}
$$

\section{Case III:}

when $f(x)=x^{3}$ and $g(x)=x^{2}$

$\phi(\mathrm{x}, 0)=\mathrm{x}^{3}+\mathrm{ct}^{2}$,

using the above equation we have

$A_{1}=6 x+2 c t$, and $B_{1}=3 x^{2}+2 c t x$

$\phi(x, 1)=\frac{9}{2} x^{2} t^{2}+\frac{2}{3} c^{3} t^{3}$,

Now $A_{2}=0$ and $B_{2}=\frac{9}{2} c^{2} t^{2}$

so $\phi(x, 2)=\frac{3}{8 x} c^{4} t^{4}$,

and so on. Therefore, 


$$
\begin{aligned}
\phi(x, t)= & \phi(x, 0)+\phi(x, 1)+\phi(x, 2)+\phi(x, 3)+\ldots . \\
& =x^{3}+c x^{2}+\frac{9}{2} x^{2} t^{2}+\frac{2}{3} c^{3} t^{3}+\frac{3}{8 x} c^{4} t^{4}+\ldots . . \\
& =x^{3}\left[1+c\left(\frac{t}{x}\right)+\frac{9 c^{2}}{2}\left(\frac{t}{x}\right)^{2}+\frac{2 c^{3}}{3}\left(\frac{t}{x}\right)^{3}+\frac{3 c^{4}}{8}\left(\frac{t}{x}\right)^{4}+\ldots .,\right]
\end{aligned}
$$

The above series will be convergent for $|\mathrm{t} / \mathrm{x}|<<1$. i. e. for a small range of time and large membrane

\section{Case IV:}

When $f(x)=x^{2}$ and $g(x)=x$

$\phi(\mathrm{x}, 0)=\mathrm{x}^{2}+\mathrm{ct} \mathrm{x}$,

by using the above value, we have

$\mathrm{A}_{1}=2$, and $\mathrm{B}_{1}=2 \mathrm{x}+\mathrm{ct}$

$\phi(x, 1)=2 c^{2} t^{2}+\frac{1}{6 x} c^{3} t^{3}$,

now $A_{2}=\frac{c^{3} t^{3}}{3 x^{3}}$, and $B_{1}=-\frac{c^{3} t^{3}}{6 x^{3}}$

$\phi(x, 2)=\frac{1}{120 x^{3}} c^{5} t^{5}$

$\phi(x, 3)=\frac{1}{560 x^{5}} c^{7} t^{7}$,

and so on. Thus,

$\phi(\mathrm{x}, \mathrm{t})=\phi(\mathrm{x}, 0)+\phi(\mathrm{x}, 1)+\phi(\mathrm{x}, 2)+\phi(\mathrm{x}, 3)+\ldots$.

$$
\begin{aligned}
& =x^{2}+c t x+2 c^{2} t^{2}+\frac{1}{6 x} c^{3} t^{3}+\frac{1}{120 x^{3}} c^{5} t^{5}+\frac{1}{560 x^{5}} c^{7} t^{7}+\ldots . \\
& =x^{2}\left[1+c\left(\frac{t}{x}\right)+2 c^{2}\left(\frac{t}{x}\right)^{2}+\frac{c^{3}}{6}\left(\frac{t}{x}\right)^{3}+\frac{c^{5}}{120}\left(\frac{t}{x}\right)^{5}+\frac{c^{7}}{560}\left(\frac{t}{x}\right)^{7}+\ldots .\right],
\end{aligned}
$$

As Case I and III the above series is also convergent for $|\mathrm{t} / \mathrm{X}|<<1$.

\section{Case V:}

When $f(x)=x^{2}$ and $g(x)=x^{2}$

$\phi(\mathrm{x}, 0)=\mathrm{x}^{2}+\mathrm{ct}^{2}$,

from the above equation we have,

$\mathrm{A}_{1}=2+2 \mathrm{ct}$, and $\mathrm{B}_{1}=2 \mathrm{x}+2 \mathrm{xct}$,

$\phi(x, 1)=2 c^{2} t^{2}+\frac{2}{3} c^{3} t^{3}$,

$\mathrm{A}_{2}=0$, and $\mathrm{B}_{2}=0$,

$\phi(\mathrm{x}, 2)=0$,

so we can write, 
$\phi(\mathrm{x}, \mathrm{n})=0, \quad \mathrm{n} \geq 2$

thus we have the solution of the form,

$$
\begin{array}{r}
\phi(\mathrm{x}, \mathrm{t})=\phi(\mathrm{x}, 0)+\phi(\mathrm{x}, 1)+\phi(\mathrm{x}, 2)+\ldots . \\
=\mathrm{x}^{2}+\mathrm{ctx}^{2}+2 \mathrm{c}^{2} \mathrm{t}^{2}+\frac{2}{3} \mathrm{c}^{3} \mathrm{t}^{3}
\end{array}
$$

\section{Case VI:}

when $f(x)=\sqrt{x}$ and $g(x)=\frac{1}{\sqrt{x}}$

$\phi(\mathrm{x}, 0)=\sqrt{\mathrm{x}}+\frac{\mathrm{ct}}{\sqrt{\mathrm{x}}}$,

by using the above values, we have

$\mathrm{A}_{1}=-\frac{1}{4 \mathrm{x}^{3 / 2}}+\frac{3 \mathrm{ct}}{4 \mathrm{x}^{5 / 2}}$, and $\mathrm{B}_{1}=\frac{1}{2 \mathrm{x}^{1 / 2}}-\frac{\mathrm{ct}}{2 \mathrm{x}^{3 / 2}}$,

$\phi(x, 1)=\frac{c^{2} t^{2}}{8 x^{3 / 2}}+\frac{1}{24 x^{5 / 2}} c^{3} t^{3}$,

now

$A_{2}=-\frac{15 c^{2} t^{2}}{32 x^{7 / 2}}+\frac{35 c^{3} t^{3}}{96 x^{9 / 2}}$, and $B_{2}=-\frac{3 c^{2} t^{2}}{16 x^{5 / 2}}-\frac{5 c^{3} t^{3}}{48 x^{7 / 2}}$,

$\phi(x, 2)=\frac{3 c^{4} t^{4}}{128 x^{7 / 2}}-\frac{5 c^{5} t^{5}}{384 x^{9 / 2}}$,

Similarly, with the help of $A_{3}$ and $B_{3}$ we find $\phi(x, 3)$,

$$
\begin{aligned}
\phi(x, 3)= & \frac{49 c^{6} t^{6}}{5120 x^{11 / 2}}+\frac{135 c^{7} t^{7}}{21504 x^{13 / 2}} \\
\phi(x, t)= & \phi(x, 0)+\phi(x, 1)+\phi(x, 2)+\ldots . . \\
= & \sqrt{x}+\frac{c t}{\sqrt{x}}+\frac{c^{2} t^{2}}{8 x^{3 / 2}}+\frac{1}{24 x^{5 / 2}} c^{3} t^{3}+\frac{3 c^{4} t^{4}}{128 x^{7 / 2}}+\frac{5 c^{5} t^{5}}{384 x^{9 / 2}}+\frac{49 c^{6} t^{6}}{5120 x^{11 / 2}}+\frac{135 c^{7} t^{7}}{21504 x^{13 / 2}}+\ldots . \\
= & \sqrt{x}\left[1+c\left(\frac{t}{x}\right)+\frac{c^{2}}{8}\left(\frac{t}{x}\right)^{2}+\frac{c^{3}}{24}\left(\frac{t}{x}\right)^{3}+\frac{3 c^{4}}{128}\left(\frac{t}{x}\right)^{4}+\frac{5 c^{5}}{384}\left(\frac{t}{x}\right)^{5}\right. \\
& \left.\quad+\frac{49 c^{6}}{5120}\left(\frac{t}{x}\right)^{6}+\frac{135 c^{7}}{21504}\left(\frac{t}{x}\right)^{7}+\ldots\right]
\end{aligned}
$$

as of case I, III and IV the above series is also convergent for $|\mathrm{t} / \mathrm{X}|<<1$.

For Cases I, III, IV and VI, convergence ratio of the series $\mathrm{t} / \mathrm{X}$ is to be small. for Case I and $\mathrm{VI}$, displacement is inversely proportional ' $x$ ' and directly proportional to't'. But in Case IV displacement is directly proportional to both ' $x$ ' and't'. In Case II and $\mathrm{V}$, the series consist of finite number of terms, in these cases $\phi(x, t)$ does not depend on the ratio $t / x$. In both cases displacement increases with the increase in $x$ and $t$ for a fixed value of $c=2$. FIGURE (4). (10) depicts that with the increase in $t$ and $c$ displacements increases for a fixed value of $x=25$. Rate of increase of displacement is fast in Case $V$ than in Case II.

\section{Conclusion}


The Elzaki projected differential transform method (EPDTM) is very powerful tool in order to find the solution of various linear and nonlinear problems, showing its application for vibration of very large membrane. Elzaki Projected differential transform method can be used to solve the physical and engineering problem both analytically and numerically. EPDTM also gives rapidly converging solutions. Numerical results also show the higher degree of accuracy of method.

\section{Acknowledgements}

This work is supported by the National Natural Science Foundation of China (Grant no, 11371320), Zhejiang Natural Science Foundation (Grant no, LZ4A010002), Foundation of Science and Technology Department (Grant no, 2013C31084) of Zhejiang province, and Scientific Research Fund of Zhejiang provincial education department (grant no, Y201431077 and Y2013329420).

\section{References}

[1] T.M.Elzaki, B.A.S.Alamri. Projected differential transform method and Elzaki transform for solving system of nonlinear partial differential equation, World Applied Science Journal, Vol. 32, No. 9,(2014) 1974-1979

[2] T.M.Elzaki, A solution for nonlinear system of differential equation using a mixture of Elzaki transform and differential transform method, International Mathematical Forum, Vol. 7, No. 13, (2012) 625-630

[3] Tarig. M. Elzaki, The new integral transform "Elzaki Transform”, Global Journal of Pure and Applied

Mathematics, Vol. 7, (2011) 57-64

[4] Tarig. M. Elzaki, S. M. Ezaki, Application of new transform "Elzaki Transform", to partial differential equations, Global Journal of Pure and Applied Mathematics, Vol. 7, (2011) 65-70

[6] M.Suleman, Qingbiao Wu, T. M. Elzaki, 2015. Approximate analytic solution of fuzzy Riccati differential equation using Elzaki projected differential transform method.

[7] Ahmet Yildirim, Canan Unlu, S.T.Mohyud-din, On the solution of Vibration equation by means of the Homotopy perturbation method, Application and Applied Mathematics, special issue No. 1, (2010) 24-33

[8] S. Das, A numerical solution of the vibration equation using modified decomposition method, Journal of Sound and Vibration, Vol. 320, (2009) 576-583

[9] S.T.Mohyud-din, A.Yildrim, An algorithm for solving the fractional vibration equation, Computational Mathematics and Modeling, Vol. 23, (2006) 228-236

[10] S.Tapaswini, S. Chakraverty, 2014. Non probabilistic solution of uncertain vibration equation of large membranes using Adomian Decomposition method, The Scientific World Journal, Vol. 2014, Article id 308025,

[11] Z.Zheng, J.J.Guo, W.J.Song, X.T.He, F.Lu, J.Sun, 2014. Nonlinear free vibration analysis of axisymmetric polar orthotropic circular membrane under the fixed boundary condition, Mathematical Problem in Engineering, Vol. 2014, article ID 651356

[12] Steven Errede, Vibration of circular membrane and circular plates, UIUC physics 193 POM, Physics of Musical Instruments

[13] C. Mei, The analysis and control of longitudinal vibration from wave viewpoint, ASME Journal of Vibrational Analysis, Vol. 124, (2002), 645-649

[14] Y.W.Juan, L.Wu, H.X.Sheng, L.X.Qing, 2009. Constructing and solving of Vibrating equation for human beings, Tympanic membrane, Journal of Vibration and Shock

[15] M.N.Bahrami, M.Loghmani, M.Pooyanfar, A new analytic approach for free vibration of membrane wave stand point, World Academy of Science, Engineering And Technology, Vol. 2, (2008) 283-286

[16] Tongue, Benson, 2001. Principles of Vibration, Oxford University Press

[17] Maia, Silva, 1997. Theoretical and experimental model Analysis, Research Studies Press

\section{FIGURES}

FIGURE 1: Plot of $\phi(x, t)$ with respect to $x$ and $t$ at $c=8$ for Case I 

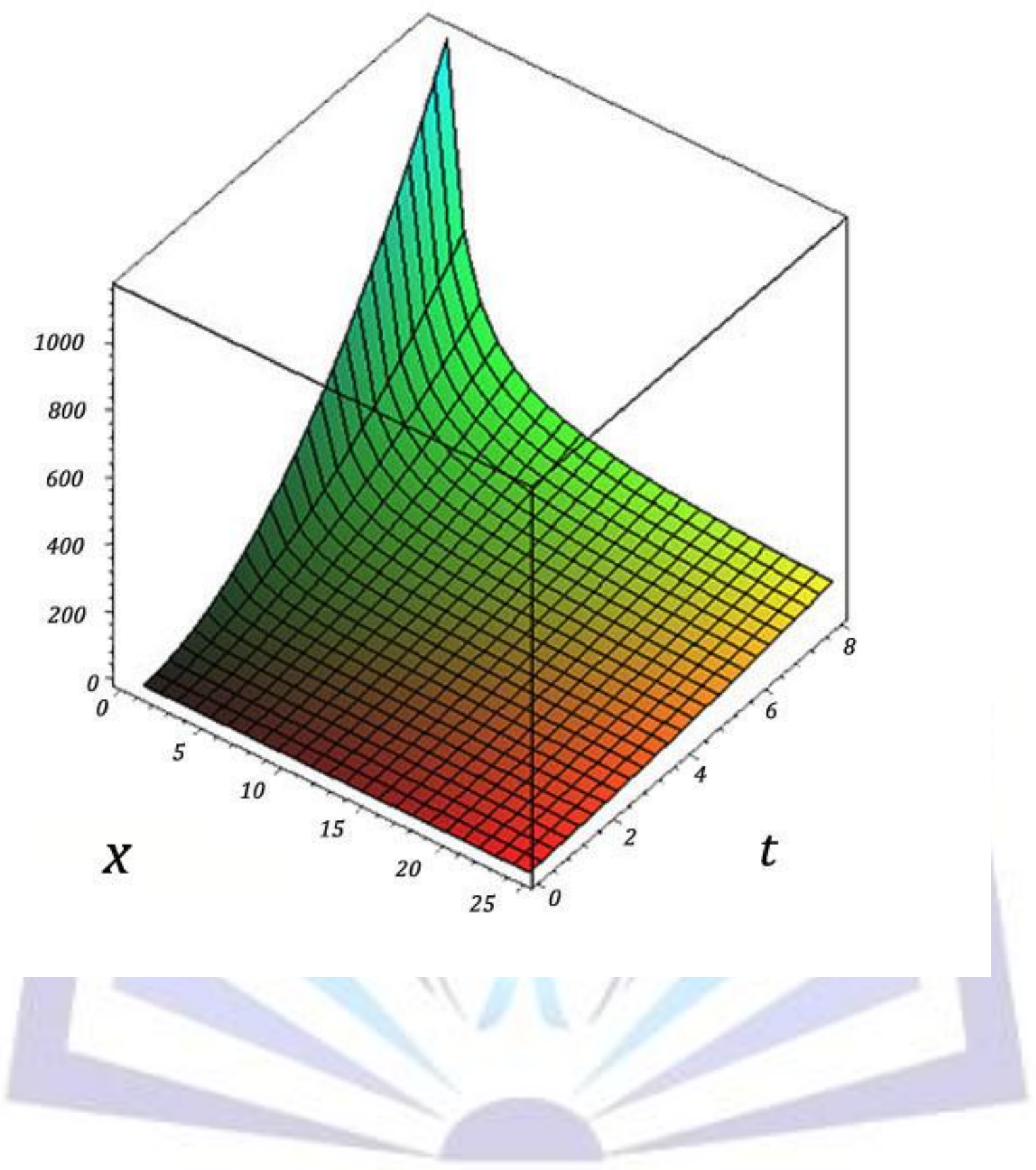

FIGURE 2: Plot of $\phi(x, t)$ vs. $t$ for different values of $c$ at $x=25$ for Case I 


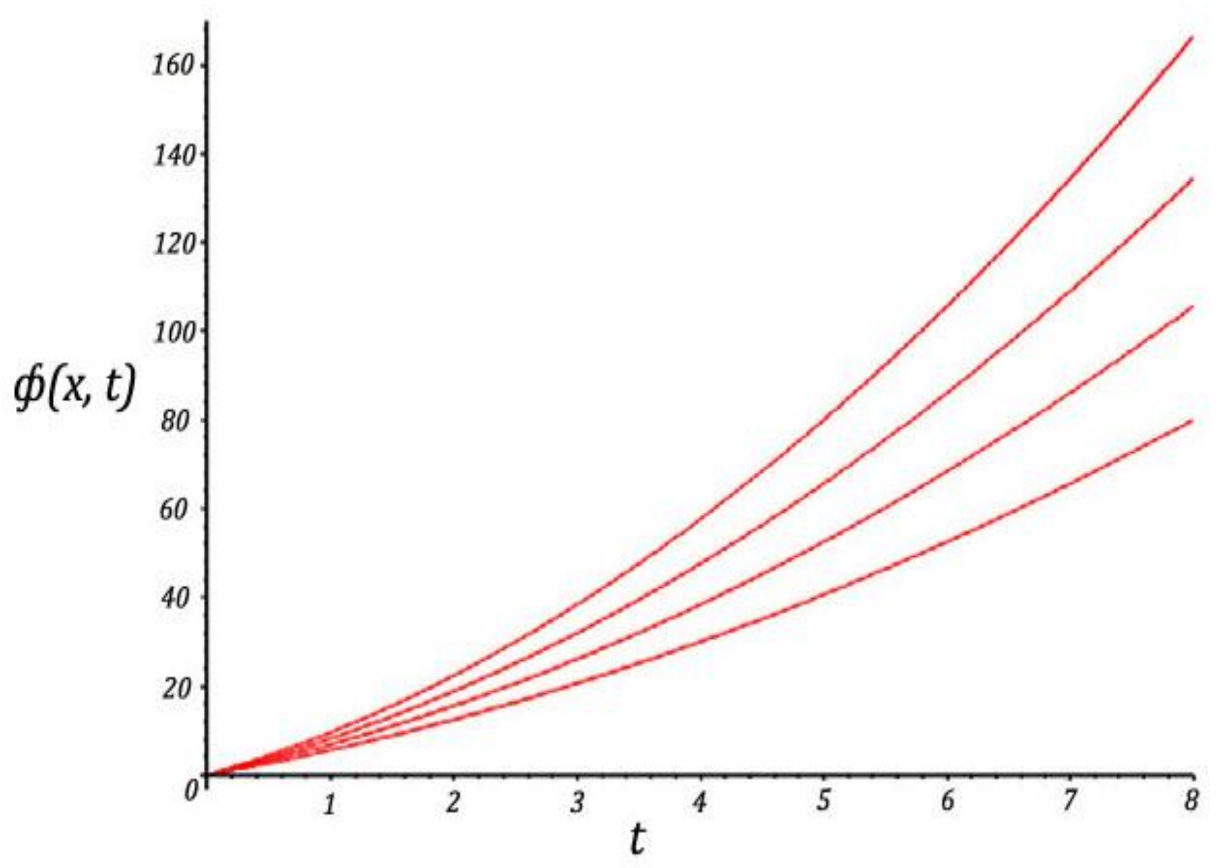

FIGURE 3: Plot of $\phi(x, t)$ with respect to $x$ and $t$ at $c=8$ for Case II

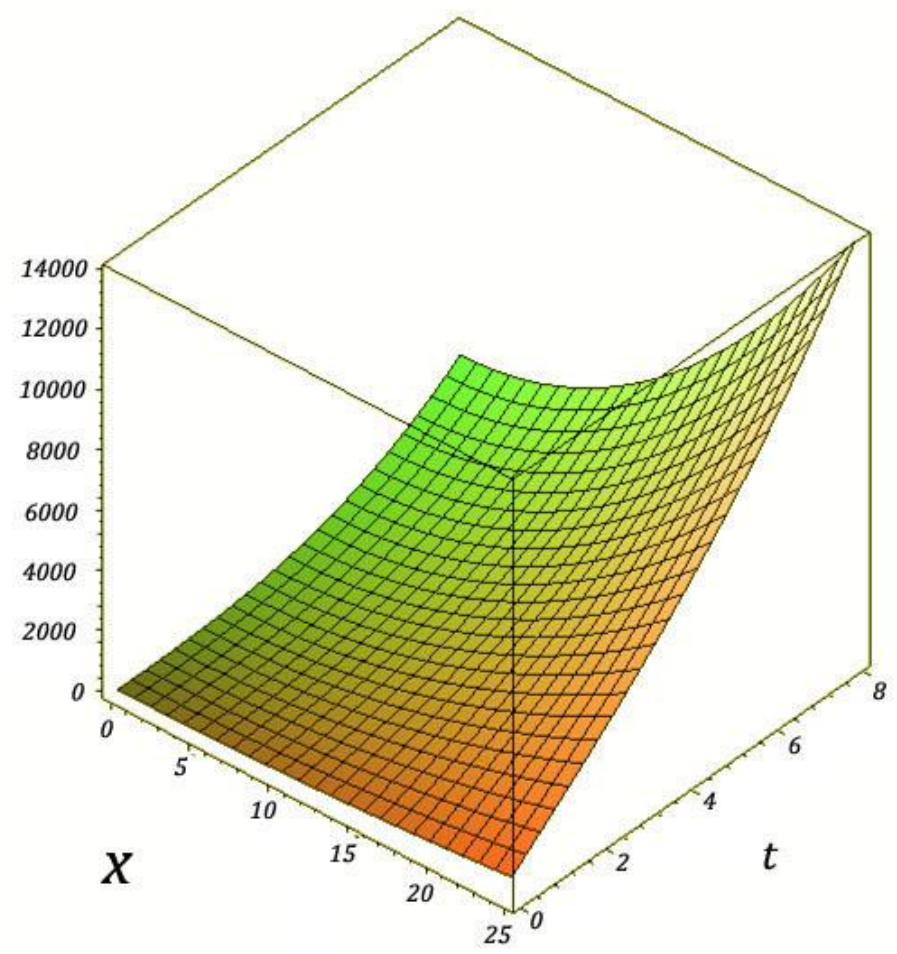

FIGURE 4: Plot of $\boldsymbol{\phi p}(\mathbf{x}, \mathbf{t})$ vs. $\mathbf{t}$ for different values of $\mathbf{c}$ at $\mathbf{x}=\mathbf{2 5}$ for Case II 


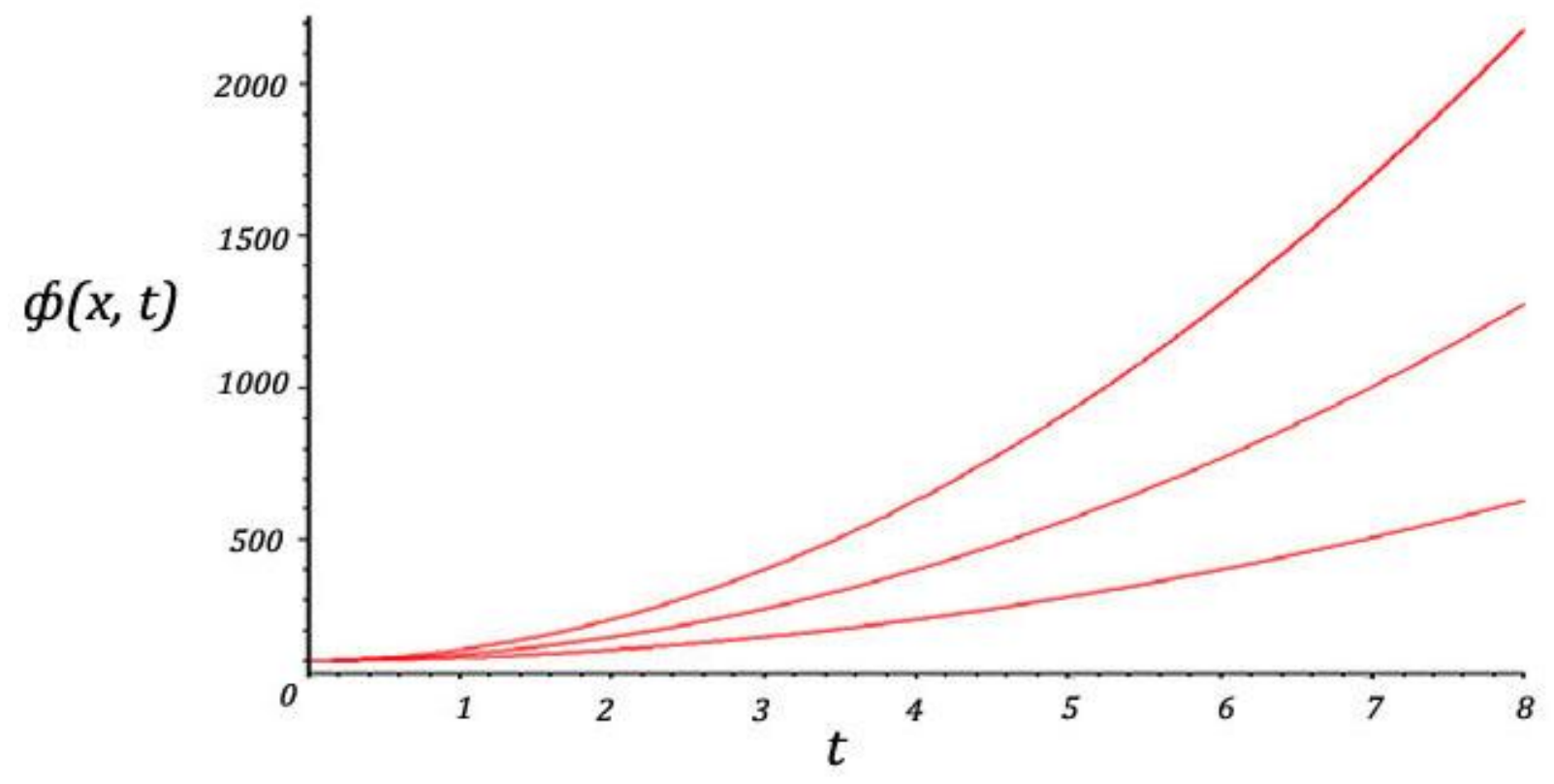

FIGURE 5: Plot of $\phi(x, t)$ with respect to $x$ and $t$ at $c=4$ for Case III

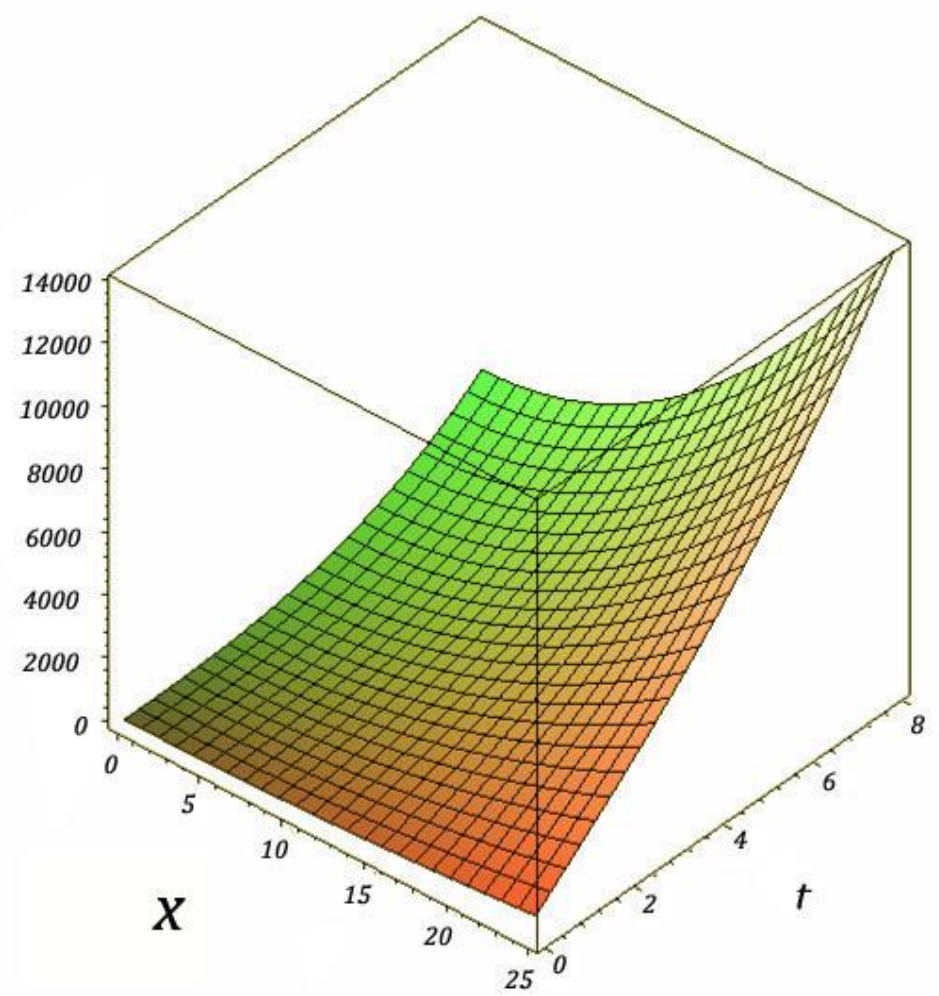

FIGURE 6: Plot of $\phi(x, t)$ vs. $t$ for different values of $c(c=2,3,4)$ at $x=25$ for Case III 


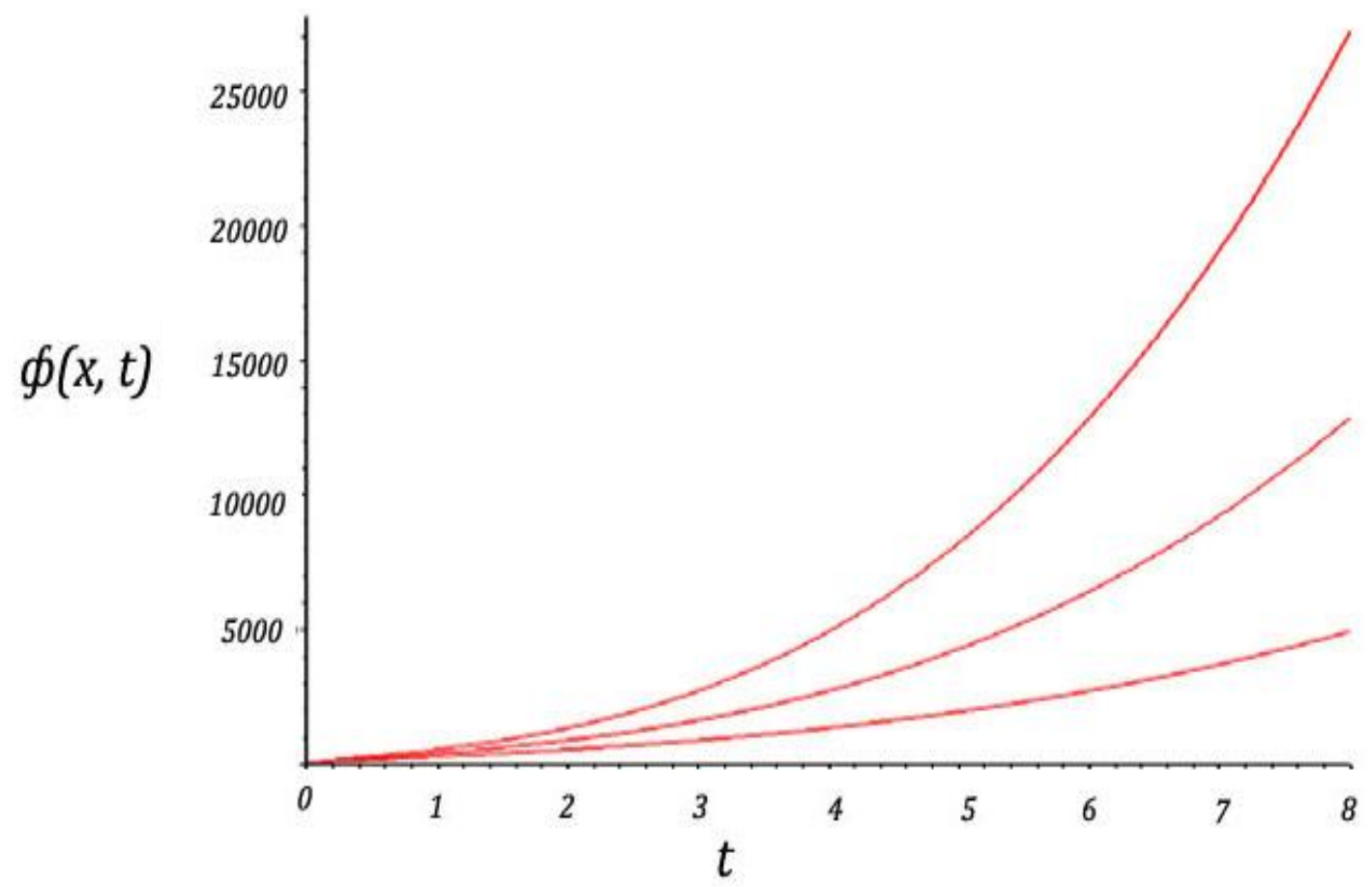

FIGURE 7: Plot of $\phi(x, t)$ with respect to $x$ and $t$ at $c=8$ for Case IV

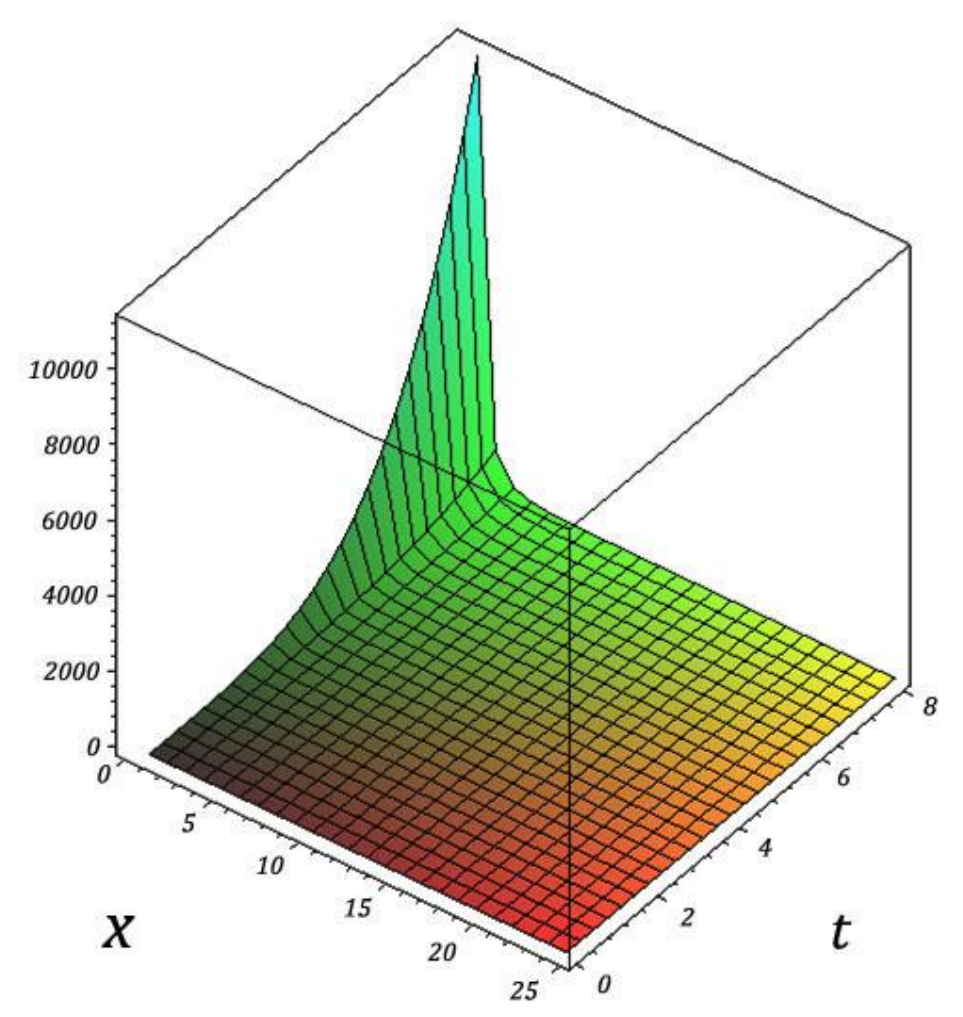

FIGURE 8: Plot of $\phi(x, t)$ vs. $t$ for different values of $c$ at $x=10$ for Case IV 
FIGURE 1: Plot of $\phi(x, t)$ with respect to $x$ and $t$ at $c=4$ for Case $V$

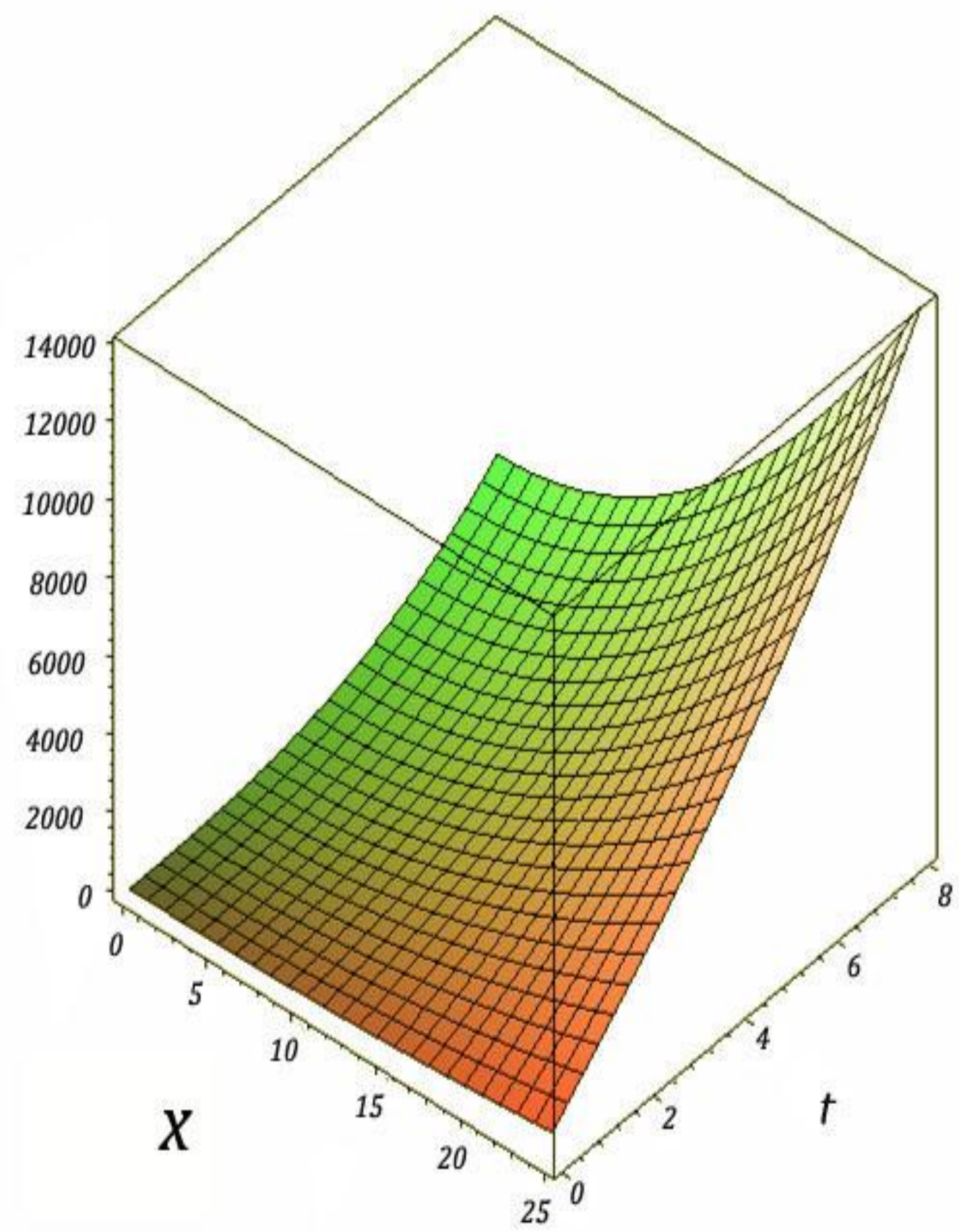

FIGURE 10: Plot of $\phi(x, t)$ vs. $t$ for different values of $c(c=2,3,4)$ at $x=25$ for Case $V$ 
FIGURE 11: Plot of $\phi(x, t)$ with respect to $x$ and $t$ at $\mathbf{c}=\mathbf{8}$ for Case VI

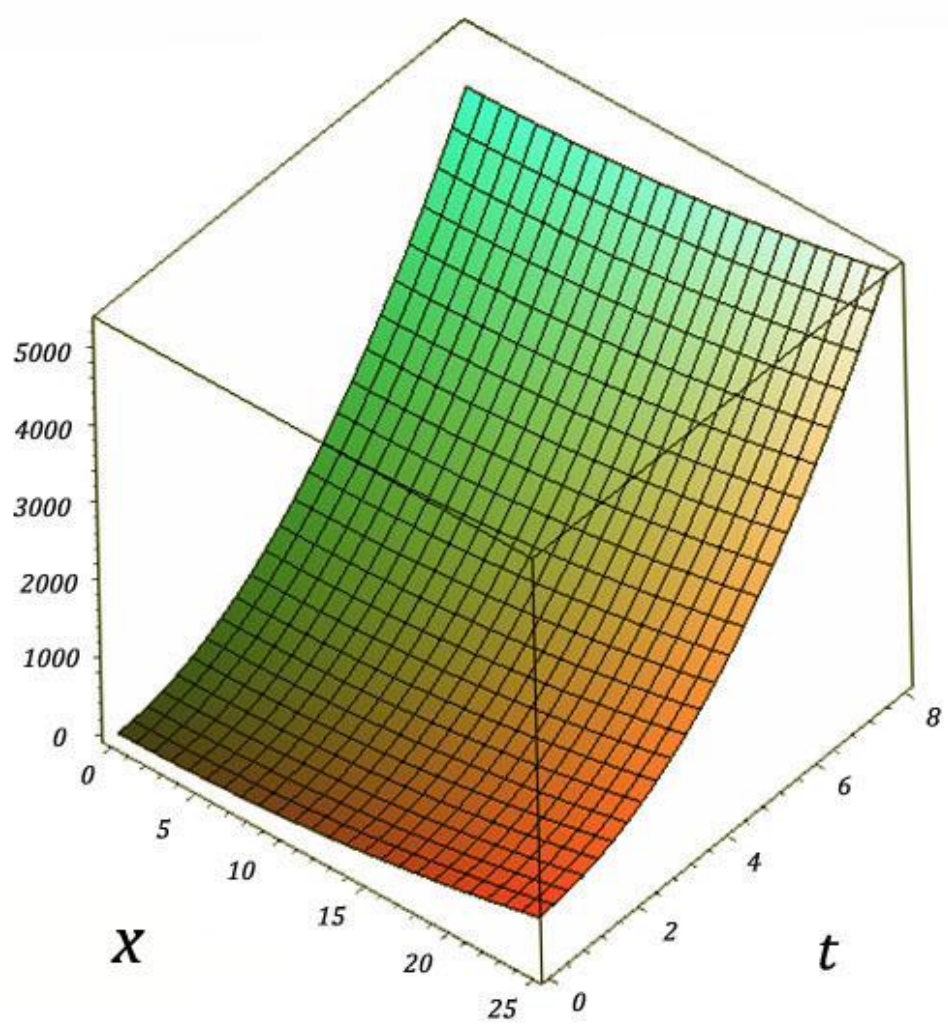

FIGURE 12: Plot of $\phi(x, t)$ vs. $t$ for different values of $c$ at $x=10$ for Case VI

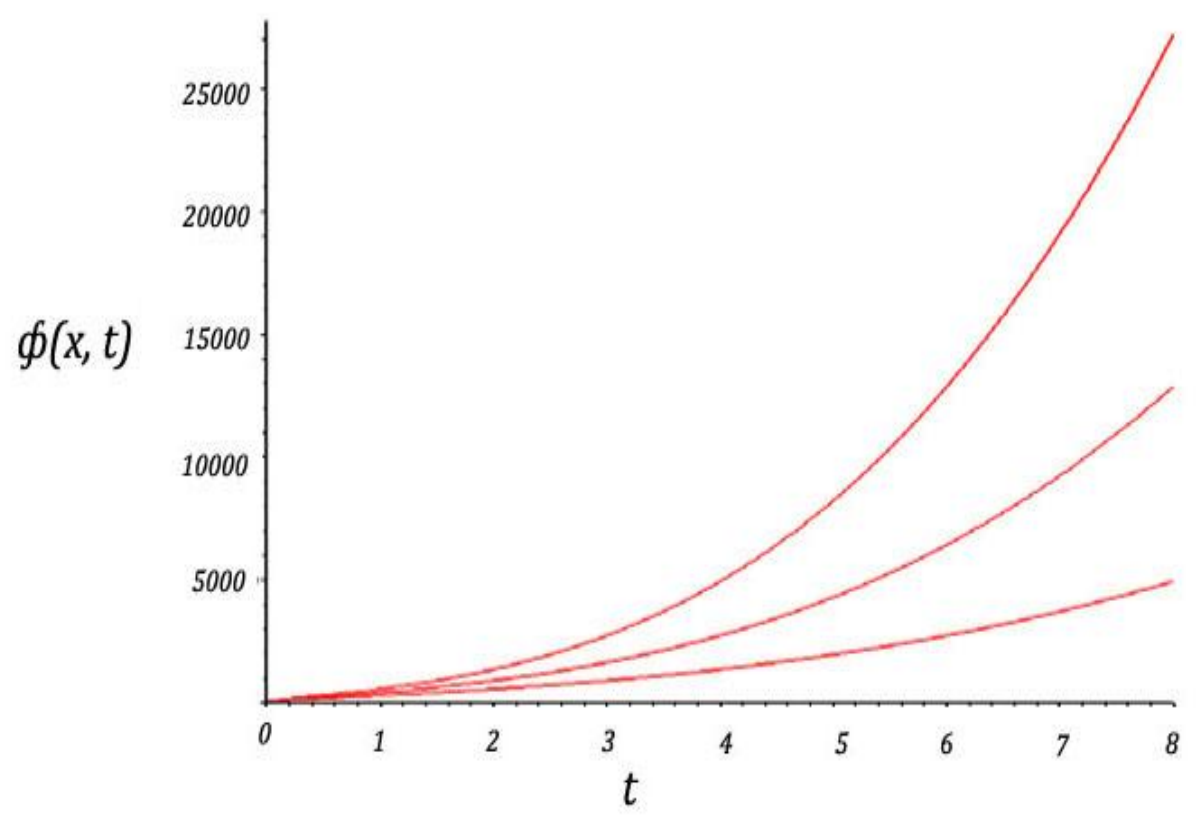

